\title{
9 Teaching Ancient Jewish History: An Experiment in Engaged Learning
}

\author{
Michael L. Satlow
}

For a little over fifteen years, I have been teaching (and writing about) rabbinic literature and its historical context to college undergraduates and graduate students, as well as to adults in (mostly Jewish) formal and informal contexts. It was, quite predictably, my own experiences as a student of Jewish history that drew me into the field; the experience of encountering a past that was so much more complex, foreign, and human than the one I learned about in my own Jewish education was thrilling. It is an excitement that remains with me and continues to invigorate me as a human being and a Jew ${ }^{1}$ —and that I earnestly want to convey to my students.

Yet while I would be delighted to have my college students leave my classes excited and stimulated by the material, that cannot be the sole or even primary goal of an introductory level college class. In such a class, my primary goal is to get students to think historically about the Jews of antiquity. This means overcoming the general challenges presented by widespread unfamiliarity with both historical thinking and antiquity itself, while at the same time training students to make sense of scattered and discrete primary documents in relationship to each other and their wider context. Ultimately, my goal is also to help students develop critical thinking skills that they might then apply more generally, both to their own personal lives and their academic ones.

For most of my career, I have believed that I have been reasonably good at this. I have generally arranged my introductory class to early

1 For a fuller discussion of how the academic study of Jews and Judaism can enrich one's Jewish life, see Michael L. Satlow, Creating Judaism: History, Tradition, Practice (New York: Columbia University Press, 2006), 288-96. 
Jewish history as a chronological narrative, moving from the building of the Second Temple around 520 BCE to its destruction in 70 CE. Prior to most classes, students would read a selection of primary and secondary texts and complete a short writing assignment that they would email to me. Class time would be split between lecture and discussion. The level of discussion was generally high, students seemed prepared and engaged, and course evaluations were very good.

But over the past few years I have had gnawing doubts about the success of this course. My primary goal was to have the students master not a single synthetic narrative, but a set of intellectual skills that they could apply to other (previously unseen) data. Historical thinking, as Sam Wineburg felicitously puts it, is an "unnatural act." Through primary and secondary school, to say nothing of popular books and culture, most of us come to understand history as a simple narrative of the past. Yet for most historians, the core of the historical enterprise is less the narrative than it is the interpretive encounter between the reader and her documents. The goal of historical thinking-as practiced by professional historians and teachers - is not a single narrative but the opening of multiple perspectives onto a distant and perhaps ultimately unknowable past. History, Wineburg claims, is used best to teach not single, coherent, and "definitive" narratives, but rather "humility in the face of our limited ability to know, and awe in the face of the expanse of human history." 3

Was I succeeding? If the measure of my teaching effectiveness was the quality of student work at the end of the semester, I was falling short of my self-expectations. Their final exams were designed to measure not simply student recall but also their ability to synthesize the material in new ways, and I was often largely disappointed by their answers. My prepared, engaged, and smart students could recall material with ease, but had much more difficulty applying what they learned in class to new data.

Perhaps, though, I was not teaching them how to do this. I have long been aware of the research arguing for the effectiveness of active

2 Sam Wineburg, Historical Thinking and Other Unnatural Acts: Charting the Future of Teaching the Past, Critical Perspectives on the Past (Philadelphia: Temple University Press, 2001).

3 Ibid., 24. 
over passive learning. As summarized by Derek Bok, "students recall only 42 percent of the information in a lecture by the time it ends and only 20 percent one week later." ${ }^{4}$ Lecturing might inspire and in some sense "model" critical thinking, but as a pedagogical technique for conveying both information and critical thinking skills, it fares rather poorly. Rather, the empirical studies suggest, active learning techniques produce better learning outcomes. Over the years, I have attempted to integrate more active and collaborative learning into my classes in order to improve my learning outcomes.

To my surprise, though, I have found that many of my students, both in the university and in adult education classes, are wary of and occasionally even hostile to active learning techniques. In my more cynical moments the term "edutainment" comes to mind, the product of a consumerist culture in which education is seen as a commodity to be purchased. This is not entirely fair; active teaching forces students out of their comfort zones, and is attended by a certain level of the indeterminacy that accompanies such activities and their assessment. The issue is further complicated by the methods of teaching evaluation. In both the university and adult education contexts with which I am most familiar, professional teaching evaluation is based almost entirely on student evaluations, with some consideration given to the design of the course as demonstrated in the syllabus. After receiving one particularly scathing set of course evaluations, I turned the next year to a much more heavily lecture-based format to find my evaluations rise (and student learning fall), much to the relief of my colleagues.

With these concerns in mind, I set out to conduct a more radical experiment in active learning. I was primarily interested in exploring two clusters of questions. First, how were my undergraduate students learning, or not? Could I better identify the factors that led to final work that I often found disappointing? The second set of questions was more practical: would more active learning increase the quality of student learning, to the extent that I am able to make such judgments? This last qualifier, of course, also raises the issue of assessment in the humanities. What are we measuring, and how do we measure it?

4 Derek Bok, Our Underachieving Colleges: A Candid Look at How Much Students Learn and Why They Should be Learning More (Princeton: Princeton University Press, 2006), 123. 
This paper will begin with a description of the experiment, continue with my interpretation of the data, and end with what I think I have learned, in general as a teacher and specifically as relates to the teaching of rabbinic literature and ancient Jewish history.

\section{The Experiment and the Results}

The course that I chose for this experiment was one of my "bread and butter" courses, a historical survey of the Jews from the Persian to early rabbinic periods. This has always been a standard historical survey, focusing on political, social, and economic conditions, while at the same time foregrounding the development of "rabbinic Judaism." The class is designed to develop the historical context necessary for the later academic and historical study of rabbinic literature; in the class itself we read only a few rabbinic texts. One of the primary goals of this course, as I assume is the case with most historical surveys, is to give a broad-brush narrative of the period that will allow students to navigate the period and its data, to develop a frame of reference for historical thinking, so that in more advanced courses, when students encounter relevant data, they will better be able to put it within a context.

Yet in previous renditions of the course, students seemed not quite able to develop this frame of reference to the extent of being able to apply it to unfamiliar texts. When in final projects students were asked to interpret new data, very few would do so in relationship to the models and data presented in class. It seemed unlikely to me that students did not understand what we were covering in class; their ability to summarize, paraphrase, and critically engage materials covered in class was quite good. So I set out to discover what was not "taking" and why.

Toward this end, I radically redesigned the course. What if I no longer gave students an explicit frame of reference, but moved so radically toward an "active learning" model that they were forced to create one for themselves? Could I do this in a way that documented their learning, so at the same time I could analyze how students learned?

To answer these questions, I put a collaborative project at the heart of the course. The class, as a whole, would develop a "wiki" of early Jewish history. A wiki is an online collaboratively-written set of documents (it is the environment used, for example, by Wikipedia). I settled on a wiki for three reasons. First, it would allow students to work together 
without always having to coordinate their schedules. Second, by allowing peer editing and revision, it would open a window onto how students change their minds as the semester-and learning-progresses. Finally, every change is logged, providing a written record of the entire process.

I had no expectations concerning how this wiki would develop; I was genuinely curious and open to all possibilities. I did, though, have a hypothesis about its pedagogical effectiveness: the hands-on and intensively active approach of the course would raise the level of student learning, which in turn would be reflected in their final, individual exams. It turns out that I was wrong: their final essays did not appear to me to be any better than those in the past. Yet despite this failure, this experiment did give me some insight into the problems with which I have been struggling.

\section{The Experiment}

The class was titled "The Beginning of Judaism," and was taught during the fall of 2006 at Brown University. Nine undergraduate students, of different levels, classes, and "concentrations" (Brown's term for majors) finished the course (another two dropped the course during the semester). Both the enrollment and the drop numbers are consistent with the previous times the course was offered. We met twice a week for 80 minutes, in a room that was a bit too large for us but was set up with four tables forming a square; there were also moveable desks in the room, which we sometimes used during in-class group work. My usual place was the side of the table closest to the blackboard; I was the only person sitting on this side. The room had technology hook-ups that we occasionally used to present images and to review progress on the wiki.

At the beginning of the semester, students received a syllabus that included a detailed description of the substantive content of the course as well the structure of the class. ${ }^{5}$ The substantive course description at the beginning of the syllabus read:

Prior to $586 \mathrm{BCE}$, the Israelites worshipped a warrior God who, they said, had forged them into a nation and continued to protect

5 Five evaluations comprised their final grade: Preparation and attendance ( $10 \%$ of final grade); reading journal entries (20\%); midterm essay (15\%); the wiki (30\%); final take-home exam (25\%). 
them: He was their king, and they were His subjects. In allegiance to this God, whom they called YHWH, they regularly offered sacrifices at their Temple in Jerusalem. When the Babylonians razed the Jerusalem Temple in $586 \mathrm{BCE}$, resettling part of the population in Babylonia, they also unintentionally sparked the transformation of the religion of the Israelites.

About a century later a "remnant" of this people returned to Jerusalem, this time as Jews. Now bringing a book they called the Torah, they began to construct a religion fundamentally different from that of their Israelite ancestors. This course is the story of how the religion of ancient Israel was transformed into Judaism. Our story starts with the building of the Second Temple and ends about 1,000 years later, with the beginning of the rabbinic movement and the creation of the patterns of thought and rituals that have lasted to the present day.

In the section on organization and structure, I wrote (in part):

The structure of this class will most likely differ from many of the historical surveys you may have taken. The first part of the class will involve becoming familiar with a narrative that attempts to make sense of the entire period and the different kinds of sources available to historians of the Jews in antiquity.

After the winter break things get more interesting, exciting, and maybe even a little scary. In the second part of the course we as a class will construct our own, possibly alternative, historical narrative. We will work on a wiki; by the end of the semester we should have a history that we can then make publicly accessible. Work on the wiki will be ongoing.

In preparation for most classes, you will do the assigned reading and write a (usually short) entry in your reading journal on Mycourses [Brown's online course management system]. We will then discuss the readings in class, and afterwards you-or the class as a whole or your group, as appropriate-will add to the wiki (also drawing, if appropriate, from your reading journal). For many classes, smaller groups will read related but different materials, and we will use class time to integrate and synthesize these readings.

This is the first time I have tried to teach this way, and I anticipate some messiness in the process. In recognition of this, I have worked into our schedule time for class discussions of the process. 
At our first class meeting I emphasized the experimental nature of the course. Then, and throughout the course, I also explicitly stated the learning goals of the course. I told them much of what I have written above, that I had redesigned the class to emphasize active learning so that they might better be able to develop and apply a historical framework for the period.

From the first class meeting on I also explicitly emphasized that there was a "process" goal for the class. Learning to collaborate on projects is an increasingly necessary skill today, and it is hardly an innate one. Some students had prior experience completing group projects, although these were generally limited in scope and highly structured. For all of these students, the lack of structure or clear hierarchy would prove challenging.

The goal of the first three weeks was to provide students with models for what they were about to do. For 4.5 classes we discussed Shaye Cohen's book, The Maccabees to the Mishnah. ${ }^{6}$ Before each class, students would post in their on-line reading journals their reactions to the assigned reading; only I could see them. Class would consist primarily of discussion, during which I would provide some contextual lecturing but would mainly prod them with questions (e.g., What is his thesis? What evidence does he use? What exactly is the Book of Jubilees-if your mother asks, what will you tell her?). My goal here was twofold: (1) to expose students to the range of data and the methods commonly used to make sense of it, and (2) to help students internalize a method for reading scholarly, historical narratives. They had to learn, that is, a particular set of critical reading skills. We used 1.5 class meetings to go the library for an introduction to the resources available there, and to a computing classroom for hands-on training in using the wiki.

These sessions ended on February 15, and February 20 was a holiday. During this week they were to complete their midterm assignment: they read, on their own, an overlapping but alternative historical narrative, Martin Jaffee's Early Judaism. ${ }^{7}$ The assignment was to write a 5-page pa-

6 Shaya Cohen, The Maccabees to the Mishnah, second edition (Louisville, KY: Westminster John Knox Press, 1987).

7 Martin Jaffee, Early Judaism, second edition (Baltimore, MD: University Press of Maryland, 2005). 
per comparing Cohen's and Jaffee's books, focusing on how two scholars using the same material can create, structurally and substantively, different narratives. I also wanted to see if they could apply the same questions that we asked of Cohen to Jaffee's book, without my prodding. We spent class on February 22 discussing their papers and introducing the wiki.

The rest of the course was structured chronologically, and the readings were predominantly primary sources. The next three classes focused on the Persian period, during which work on the wiki began. Before each class the students were to write a response to the readings in their journals and make a contribution to the wiki. They were allowed to (but did not have to) "double dip" and use their reading journal entry as their wiki contribution. I explicitly left open the structure of the wiki as well as the nature and scope of their contributions. We spent our time in class much as we had in our discussions of the Cohen book: I would pose questions of the material, and we would discuss. Some of each class was also spent reading together through selected primary texts. I would ask and explain as we went along. I suggested to students that they use what they learned in class to go back to correct and modify what they wrote on the wiki.

We devoted the next seven classes to the Hellenistic and early Roman period. Two of these classes were structured like the earlier classes (e.g., one reading with one class discussion), but five used a different format. For these classes, all of the students did one common reading, but each student was also assigned to one of three "reading groups" that had its own additional reading selection. Our class-time would be divided between three activities. Usually I would give a short lecture or lead discussion about the common reading. Then students broke up into their groups to discuss their readings. Finally, students taught their readings to the class. (In the next section of this paper, I will describe the styles of these presentations and how they changed.) These classes brought us to the spring break in late March, and then some interruptions for Passover in early April.

The week after our discussion of the Dead Sea scrolls we had a "sectarian summit." Students did not post to the wiki that week, but instead each was assigned to a sectarian group: Pharisees, Sadducees, Essenes, authors of the Dead Sea scrolls (as distinct from the Essenes, primarily 
for pedagogical reasons), ${ }^{8}$ and early followers of Jesus. Prior to class on April 17, students were expected to research their sect, both in our previously assigned readings and at the library. They were expected to consult with members of their team during this process in order to ensure broad coverage. During our April 17 class, they worked with their team, all in our classroom. I circulated among them, answered questions, and provoked them by posing arguments that I heard against them from other groups. April 19 was the summit, in which students spoke "in character." The last part of that class was a discussion and evaluation of what had happened. I then asked the teams to make appropriate postings on the wiki.

The last few classes were spent looking at the emergence of rabbinic Judaism. We returned to a single common reading and lecture/discussion format. We then had a class devoted entirely to discussing the wiki, where it was, and what needed to be done in order to finish it. The wiki was "closed" on May 10, and the students completed take-home essays a few days later. The final essay assignment was as follows.

You must answer the first question, and then you have a choice of answering either $2 \mathrm{a}$ or $2 \mathrm{~b}$.

1. In the periods that we have discussed this semester, we have returned repeatedly to the issue of religious authority and the experts who claimed it. Compare, contrast, and discuss these different forms of religious authority as demonstrated by such experts as priests, prophets, kings, scribes, and rabbis. Can you trace a line of development?

2. Answer one of the following questions:

2a. The sectarian documents from Qumran provide an internal historical narrative, albeit one that is sometimes difficult to penetrate. Primarily using the selections from the Damascus Document and Habakkuk Pesher found in

8 Our knowledge of the "Essenes" derives only from classical literary sources (e.g., Josephus, Philo, Pliny), whereas the Dead Sea scrolls never use the term "Essene". Many scholars do think that the Essenes described in the classical sources were the authors of the Dead Sea scrolls, but the identification is far from certain and I wanted the students to wrestle with the data itself. 
Texts and Traditions (on, respectively, pages 292-299 and 354-356), reconstruct the history of the sect. Your narrative need not be "correct" in the sense that it conforms to modern scholarly accounts, but it should attempt to clarify who, in the eyes of the sect, did what to whom, and when.

2b. Compare the causes of the Maccabean revolt to those of the "Great Revolt" of 66-70 CE. In what ways were they similar, and in what ways different? How do you explain the similarities and differences that you found?

\section{The Results}

This essay is a revision of a working paper that I wrote less than two months after the course had ended. In addition to drawing on my recollection, I also consulted private written notes that I kept during most of the course, as well as my entries in the contemporaneous class blog that I maintained (which students could see and were expected to read). Due to time pressure, I curtailed my entries in both media during the last third of the course. Finally, I have a record of every change made in the wiki.

The first part of the course went more or less as I have come to expect. Students would come to class having read the assigned section of the book (usually ranging from 50-100 pages), but most were unable to answer basic critical questions, such as, "What is he trying to prove, and how is he proving it?" Nevertheless, the discussions were good and interesting, with students wrestling with some of Cohen's more provocative ideas. It was clear that students either had either little prior knowledge in which to anchor this reading, or they resisted Cohen's assertions as going against some narrative to which they were already committed; many students had some unpredictable combination of the two. Students were particularly interested in his discussion of canonicity.

My blog entry for February 13 reads:

We spent most of class discussing issues of canonicity. More specifically, we discussed two levels of fluidity, in (1) establishing a 
sacred text and (2) establishing that particular text as authoritative within a given community. This brought us also to a consideration of what a "text" was in antiquity considering the high rate of illiteracy, and whether it was the text itself (i.e., the "words of God") or the ideas in that text that were primary.

There was general class interest in Cohen's argument that the establishment of scripture led to creativity. This is perhaps a thesis that we might want to consider further later in the course.

We also went over the taxonomy of the literary genres presumably "unleashed" through the canonization of Scripture, translation, paraphrase, and commentary, and considered how these forms might have supplemented, replaced, or modified understandings of the biblical text.

The quality of the midterm papers, comparing Cohen's and Jaffee's books, was relatively predictable. Students had a hard time applying the discussions of Cohen's book to Jaffee, and many of the papers remained too superficial, comparing organization and style rather than substance. They told me that they found the assignment extremely difficult.

The discussion of the papers on February 22 was followed by a general discussion of strategy in approaching the wiki. I wrote in my notes for that day:

Toward the end of class we began to discuss the wiki. I told them that this was their project, that I was not committed to any one process, and that I would step back from the conversation and listen as they decided how to proceed. The discussion was interesting, productive, and inconclusive-they demonstrated a real reluctance to come to clear decisions about "the next (first!) step." At the end of this discussion I stepped in and summarized what I thought I heard and suggested that they organize the wiki into three categories, "Religious," "Political," and "Social." At the moment, these were to serve primarily as heuristics, not as hard categories that will need to be maintained throughout.

I thought at the time that their reluctance to make decisions was due primarily to the novelty of the project, but it turned out to set the tone for the semester. They did grow more comfortable with each other throughout the semester, but they had great difficulty in moving away from ultimately turning to me. 
The class after the first wiki entry illustrates this attitude. According to my notes for February 27:

\begin{abstract}
About half of the students made entries to the wiki prior to this class. For the most part, these were good, although they took a variety of formats. We had our first anxiety attack at the beginning of class, with one student saying he needs to know what I want him to do. In response I told them an anecdote about my experience working at an investment bank right after college, how I was given responsibilities that required me to put together a team without being told how, whom to approach, or what resources were available to me-and, of course, having no authority over anybody. I had no idea how to do this. One of the goals of our project, then, also involves process, helping students to acquire skills that could be used for future collaborative projects, although unlike many work environments I would be offering more guidance, and the ramifications are far less severe. I think that they heard that, although I predict that this will not be the last panic attack. We then went relatively carefully through the book of Haggai.
\end{abstract}

Over the next several class meetings students continued to add, somewhat helter-skelter, notes and entries to the wiki. Two things began to strike me about these entries. First, there was almost no revision of previous entries. I suggested in our class blog for March 1 that students revise some entries in light of our class discussion (although I did not tell them what to revise). This suggestion went entirely unheeded. By March 13 I was growing concerned.

I wrote (in part) in my notes after class that day:

Before class I was growing concerned about the wiki. They were adding to it, but they were not editing mistakes nor at all integrating their contributions. I opened class by saying that we would talk for the first 20 minutes about the wiki-how did they think it was going? I stayed out of this conversation as they very quickly voiced to each other the same concerns that I had, and I was very pleased to see them quickly come to an agreement that they needed to meet in teams outside of class to work through some of the problems.

I made a class blog entry that day that summarized our discussion. 
In the classroom, the small group discussions tended to go well. Although this was a small class to begin with, breaking the group down into smaller groups of three to four students really did help them to discuss and engage the readings. For the first two such classes, after group discussions I would reconvene the entire class and give each group 10 minutes to teach their text to the rest of the class. These presentations did not go very well; the presenters had a hard time summarizing and conveying their texts in a way comprehensible to someone who had not read them. After these two classes, I shifted the nature of these presentations to a "jigsaw" format. After the group discussions of their texts, I would mix the groups so that each student would be responsible for teaching his or her text to two or three other students. Almost all the students thought that this worked much better.

By mid-March the wiki had a single access page that had links to three categories, "Religious," "Political," and "Social." Each of these three categories linked to a page with a list of further links. They were:

- Religious: Prophecy; Genealogy; God's Relationship to Man; God (Proofs); Ritual; Holidays and Festivals; Values; Religious Courage; Temple; Text; ECCLESIASTES (sic); Nationality and Religion; Synagogue; Special Laws 1, Philo; Circumcision.

- Political: The Role of the Priests in Haggai and Zechariah; The Attitude of Cyrus, King of Persia, towards the Judeans: Perspectives in Ezra; The People of Israel and Surrounding Cultures; The Relationship of Artazerxes (sic) to Nehemiah: Perspectives in Nehemiah; Treaty Law in Jubilees; Political and Military Strategy of the Maccabees; Foreign Rulers and Treatment of Jews; Roman Revolutions.

- Social: Conversion; Foreign Rule (Social); Ethnic Continuity; Marriage; Samaritans.

There was no order or reasoning behind this list of topics. Several of these links led to pages with more links. Students had continued to add entries (and modify a few) that interested them. Predictably, the entries were stylistically, qualitatively, and quantitatively diverse. One student enjoyed writing on political aspects, and many of those entries 
were mini-essays on specialized topics. Others wrote outlines or very brief, dictionary-style entries.

Before spring break, on March 22, we had a long discussion in class about the wiki, with several students wanting to work on cleaning up its organization. One of the more significant organizational changes was made on the "Social" page. The new categories were: Conversion and Community; Jews and Gentiles in the Persian Period; Jews and Gentiles in the Early Hellenistic Period; Jews and Gentiles in the Roman Period; Jews and Early Christianity; Race, Ethnicity, Lineage, and Heritage; Marriage, Gender, and Sexuality; Institutions, Groups, and Organizations; and Law and Customs. I will return to this recategorization below, because it seems to me to mark a critical transition from thinking in topics to thinking in themes.

During that same class, I asked how I could be most useful. Students asked me to go through the wiki and comment on individual essays. During spring break I did so, usually phrasing my brief comments on each entry in terms of questions or resources for further exploration, but occasionally pointing out factual errors. The students did not address or explore the bulk of my suggestions and directions for further exploration.

Work on the wiki stalled through most of April, due to Passover and the "sectarian summit." The latter went extremely well. It turned out to be the only class activity that drove them voluntarily into the library - which previously they seemed very hesitant to use for their projects - and they were engaged in both the preparation and the actual event.

We devoted class on April 26 to a fuller discussion of the wiki. Now students were getting more anxious; they still could not develop a clear organizational or work plan on their own. At this point I intervened strongly. We decided that there should be a looser, rather than hierarchical, system of entry to the wiki for which I would be responsible. We then created lists of what we called "Contextual Essays," "Thematic Essays," and "Names, Texts, and Other Important Things," and created teams of students to work in each category. I left it up to the team to divide the actual workload. As they finished each entry, they added it to the home page. They then were supposed to each take one final look through the entire wiki, adding cross-links and revising as they thought fit. 
The "final" version of the home page of the wiki is found at the end of this document (Exhibit A). The entries themselves are inconsistent. The essay on the Hellenistic period, for example, leads to a timeline and a brief paragraph with no cross links; the essay on the Roman period has a fuller section entitled "Historical Trajectory"; and some of the entries attempt to wrestle previously-written material into a new, and not particularly well-fitting, organization. Some, however, are truly excellent examples of synthesis. Unfortunately there were few such entries, and even they exhibit another weakness that ran through all of the entries: although I repeatedly encouraged them to, students rarely consulted non-course materials in the library, and when they did it was almost always the online version of Encyclopedia Judaica.

The class concluded with a take-home final exam. As I noted above, I was disappointed with the exams. They were not bad, but they were also no better than what I had received during previous versions of the class, which were taught more conventionally.

\section{Discussion}

In one sense, this course could be considered a benign failure. Students learned no less than in previous years, and perhaps, in ways I am unable to measure, they took away more from it. It entailed, however, a tremendous amount of work on my part and theirs, with the uncertainty and social issues involved in group work raising student anxiety levels. I know that I would not repeat the course in exactly the same format.

Yet I learned much from teaching this course, and suspect that I will learn even more over the years as I reflect further on the experience and the data. Below are some preliminary reflections on both broad pedagogical issues and more practical and applied ramifications.

\section{Narratives vs. Data}

For most students, "history" means a narrative. One of the primary goals of any history class at the college level is to show that "history" is in fact many narratives, each of which is the human product of the interaction of the historian with data. To do history, then, is not to learn a single narrative but to participate in an ongoing and dynamic encounter 
with the past. Rather than developing a single narrative, the teacher of an introductory historical survey might better establish a series of frames of reference, both factual and methodological.

For ancient Jewish history in particular (but not uniquely), students arrive with a very incomplete and often misguided set of frames of reference. The issue and the challenges that it presents might be highlighted by comparison to the study of American history. In one experiment, Sam Wineburg put a series of primary historical documents dealing with Abraham Lincoln in front of several students and teachers and asked them to think aloud about these documents. ${ }^{9}$ The results were illuminating, primarily in revealing the ways that prior education shapes the contexts we develop to make sense of new data. Yet while these documents frequently challenged prior understandings (e.g., by suggesting that Lincoln believed that blacks were inferior to whites), all of the participants in this experiment had a rich (if sometimes incorrect) frame of reference for making sense of the documents: they all knew the name Abraham Lincoln, had heard of the Civil War, and knew something of the issue of slavery and emancipation. Compare this to documents that mention or deal with Haggai, Qumran, Bar Kochba, or even the Talmud-for most students, these exist unmoored from any time or space.

My experience in this course helped me articulate what I had inchoately suspected. On the one hand, students had no context for the data, so they could make no sense out of these historical texts and artifacts. On the other hand, providing a context through reading and lectures is largely passive learning that rarely enables students to apply it to new data. I was most struck by the fact that despite reading, discussing, and writing on two narrative histories, students were unable-the very next day-to fit primary data into the contexts provided by the histories. Instead, they approached the material from the ground up, thinking in discrete topics and struggling to find the right tools for interpreting the ancient data. That is, when confronting an ancient text, even one that was discussed in the secondary work they had previously read, students rarely would say something like, "This is an example of what Jaffee refers to as...." Instead, they might read a text for the central message or

9 Wineburg, Historical Thinking, 89-112. 
thesis and in the process ignore the text's most important aspects, at least to the historian.

It was in the move from topical to thematic thinking that I began to see a deepening understanding. I was intrigued by this shift and what it might indicate about student learning. If the progress of the wiki can serve as any indication of student learning more generally, it suggests that the passive learning of frames of reference-even when discussed and written about-is not very effective. This, then, leads me to a hypothesis: students begin to build their understanding from wrestling with data with the tools that they already have. They begin to abandon these tools and try others as they see them fail. Here the classroom discussions were vital primarily for giving students an opportunity to be wrong, and thus learning how their existing critical tools are not good for answering certain questions. Only then do they more easily try new approaches, and even then slowly.

\section{Critical Thinking}

This experience has also helped me to articulate what I meant by my notions of "critical thinking," which is of course a notoriously vague concept. What I really wanted was not for students merely to be able to regurgitate what they were told, but for them to internalize some frame of reference to the point that they would be able to apply it to develop a context for new data; expand it to fit to new situations; explain how and why it works; and critique its weaknesses. As most college teachers in the humanities know, designing not only a course but also tools that accurately assess achievement of these goals is extraordinarily challenging. As Derek Bok notes from his survey of the empirical literature ${ }^{10}$ in actuality few teachers even try.

It is precisely this issue that might account for differences in grade distributions between the sciences and the humanities. The thrust of many courses in the sciences is applying methods to new data to achieve results. These results are often quantitative, giving instructors an easy way to ascertain a student's ability to correctly apply the new tools. That is, the intellectual process - learning new tools and acquiring the ability to apply them correctly-is the same in the humanities and the quanti-

10 Bok, Our Underachieving Colleges, 110-127. 
tative sciences, but its success is easier to judge in the sciences. Hence, it is not surprising that grade distributions in the sciences tend to be lower than in the humanities, not because there is something intrinsically harder about the sciences, but because there is a more accurate measure of achievement.

In light of my last reflection, though, I wonder if striving for this level of mastery and application in an introductory humanities class is not too ambitious. One of the problems with the wiki assignment, I now realize, was that it involved not only application of critical tools but the actual creation of new knowledge, and this was beyond what most students at this level were capable of doing. Even striving for application might be unrealistic, especially given student expectations of workload (at Brown, students expect to spend at most 4-6 hours a week on workload in a humanities class, and quite a bit more in their science classes). Perhaps a more realistic goal would be to strengthen general historical reasoning skills while providing a broad familiarity with and context for the artifacts of early Jewish history. Further development of this context into causal narratives, then, could largely wait for more advanced courses.

\section{Collaborative Work}

If I remember correctly, over my four years of college I was not assigned a single collaborative project. Nor did my teachers even once break a class into smaller discussion groups. As I told my students one day in class, only after college and upon entering the workforce, when I was immediately plunged into collaborative projects at which I was expected to succeed, did it begin to occur to me that I was entirely unprepared for it.

There is wide agreement among educators, especially outside of the universities, that collaborative work is pedagogically effective. Even studies at the college level, particularly in the sciences, have shown dramatic improvements in learning in classes that require collaborative work. Equally important, outside of academic life there are few careers in which one's success does not depend on successful collaboration. Yet although group work is more common today in colleges than when I was student (most, but not all, of my students had previously participated in one or two other collaborative experiences), it is still far from widespread. 
The reasons for this are not hard to discern and all reflect legitimate concerns. Group work can be logistically complicated (sometimes by the complexity of student schedules, or something as mundane as the bolted chairs in a lecture hall); it involves the loss of faculty control over the classroom, which in turn leads both to the fear that students are chatting or replicating mistakes rather than learning and to a degree of faculty guilt at not being more active in the classroom; groups proceed at different paces, with some finishing sooner than others; and perhaps most importantly, there is the looming issue of assessment and fairness to individual students.

At the end of this class I was particularly struck by which group assignments succeeded, and which did not. Small group discussions of the readings were almost always successful. The room and class were small enough that I could remain aware of all the groups, and most of them at most times were genuinely working. When these individual discussions sometimes stalled I stepped in to provide a provocative question, which would reignite them. Class discussions after group work, as well as the remixing of groups, were also far more successful than either a class discussion after my lecture or student presentations to the class. The most successful collaborative project was the sectarian summit, and the least was the wiki.

Now, it is this last observation that requires explanation. The summit was not actually a graded assignment per se (except as a part of overall class participation), whereas the wiki counted for a good deal of their final grade. As I had made clear to the students, the class grade on the wiki was also going to be their individual final grades on it (counting for $30 \%$ of their overall final grades), although based on their individual contributions (which I could track and document) I reserved the right to adjust their individual grades. This, however, was not incentive enough for them to organize and work well together. Two or three times students did raise in class the issue of assessment for their work on the wiki, but most students did not appear very concerned by this.

There are several possible explanations for why student collaboration on this project was not better. Comparing the wiki to the summit, though, highlights what I think are the two most salient explanations. First, I laid out well-defined criteria for the summit; I told them what I wanted from them, when I wanted it, and how to do it. I gave them 
means, a vision of the outcome, and a deadline. The wiki was far more open, as I was asking them to develop these things on their own. Such project indeterminacy is of course common in the "real world," sometimes by design and sometimes due to poor management, and some of my students were excited by it. Most, however, found it too overwhelming. Similarly, the small group discussions always improved when I posed sharper questions. This might seem rather obvious, but it emphasizes for me the importance of the teacher's (and manager's) role in setting the most advantageous conditions for collaboration.

The second, more surprising, difference was in the area of presentation and assessment. I might be pushing the data a little, but it seems to me that students were less concerned with their grade on the wiki than they were with performing well in direct competition with their classmates. Perhaps the fear of being shamed before their own peers (or, phrased positively, the desire to best them "on the field") was more of an incentive than a grade, even when they knew that the wiki was a public document. I noticed no differences between genders either. Obviously, different incentives work better for different students, and I am not yet sure what the practical "take away" message of this explanation is, but at least it suggests that issues of assessment do not play as important a role for students in their attitude toward group work as is sometimes thought.

\section{Practical Conclusions}

This experiment, although not the success for which I had hoped, still left me with two clusters of insights: the first is more broadly pedagogi$\mathrm{cal}$, and the second has to do with the use of technology in the classroom.

First, I continue to struggle with the problem of teaching students with little prior knowledge a context for interpretation, while doing so in a way that sticks. In my own courses as an undergraduate and graduate student, history classes that provided a (usually strong) narrative delivered through lecture and reading and then supplemented with discussions of primary texts largely "worked" for me; as a teacher, though, I find that the students for whom this continues to work are relatively few. I have no reason to doubt the research that indicates that active learning provides far better teaching outcomes. 
But how is active learning to be incorporated effectively into such learning environments, on whatever topic or level? That is, the issue that I face in this class is almost identical to the one present in my adult education classes, my other history classes, and my classes on rabbinic texts. While I do not yet have an answer to this question, I have learned that active learning still requires intensive teacher intervention. Finding the right balance of student empowerment and faculty guidance remains the challenge.

I suspect that a better approach incorporates the elements of the class that were successful (e.g. small group discussions, role play) with what might be called guided, active modeling. Even with discussions and writing assignments, the Cohen and Jaffee books passively modeled for my students the historical enterprise. This, I think, is the reason that it did not stick; students did not have an opportunity to work through the intellectual operations (that become innate to scholars and many teachers) for themselves. Students need to be shown how to do things (e.g., compare two texts; identify differences; models for explaining those differences) and then given the opportunity to do them, one by one and hands-on.

One practical way that this might be achieved in at least a somewhat formal educational setting might look something like this: students have a reading assignment that they are to complete while consulting a set of guiding questions and explanations. They are asked, as part of their home preparation, to complete a short written assignment that explicitly asks them to relate a primary text to a secondary one. The kind of assignment changes in order to emphasize different intellectual operations, and the operations build in complexity throughout the semester. These written assignments might then be circulated in advance. The beginning of the next class is spent discussing these assignments; they will also be collected and graded. Students then break up into small groups in order to work on a new assignment that uses different data in the same intellectual process. We then reconvene for a discussion of this exercise.

With such a model, the teacher intervenes at three points. First, there is a heavy burden of preparation. The success of the course is largely dependent on the quality and clarity of the guides and assignments. Second, the teacher is leader of class discussions, not only guiding and refereeing but also providing a learning environment in which students 
feel that it is safe to be wrong. Finally, the teacher serves as an individual coach, grading and commenting on many written assignments in order to help individual students progress according to their own needs and abilities. Supplementing a course like this with an occasional lecture, multi-media presentation (or trip to a museum), or role-playing experience like the sectarian summit could result in a fun (if labor-intensive) class both to take and to teach.

Second, an issue that emerges from this experiment more broadly deals with the effectiveness of technology. Although this class used technology extensively (e.g., online reading journals; class blog; wiki), these technologies are not ends in themselves. Technology may work best to facilitate class exercises rather than transform them. The wiki, for example, is a tool that I had hoped would facilitate collaborative work outside of class to a degree that it did not. The same exercise could have had a traditional written product with more or less the same learning outcome.

Despite my disappointment in this particular case, I remain optimistic about the ability of these technologies to facilitate both out-of-class communication and collaborative work. I suspect that with a bit more thought on my part and the proper incentives, I could better integrate this tool into my courses, providing another forum for informal writing, communication, and engagement. While I will not soon have my students again create their own wiki, I may-as suggested to me by my colleague Jordan Rosenblum - turn them loose on Wikipedia, whose entries on matters dealing with ancient Judaism and rabbinics are by and large execrable. (I would, however, use a wiki again if I were to assign collaboratively authored assignments.) The key, of course, is not to let the promise of the technology get ahead of well-considered educational goals.

I do not yet have more confidence in my success as a teacher-specifically, in having my students absorb and be able to apply a usable historical narrative- than I did when I began this experiment. Yet I am more confident than ever that a sustained focus on learning outcomes and active and engaged learning methods will ultimately lead to greater success in meeting that specific goal—which is, in some sense, my most single most important goal in teaching this survey course. It is that focus which remains at the core of my ongoing reflection on and investigation of my own pedagogy and my students' learning. 


\section{Exhibit A: Final Wiki Home Page}

Welcome to the Class Wiki of "The Beginning of Judaism" (JS53/RS63). This is a collaborative project undertaken (under compulsion) by the students of the class during spring 2007.

The Babylonian destruction of the Jerusalem temple in 587/6 BCE may have only temporarily suspended sacrifices to the God of Israel, but it also began a more fundamental transformation of ancient Israelite religion and identity. The foundations of the second Jerusalem temple were laid only 46 years after the destruction of the first, but this time by Judeans, "Jews," rather than Israelites, who increasingly relied for authority on a book-the newly redacted Pentateuch or Torah-rather than on the word of the priests. Over the following millennium this transformation would spawn an astounding diversity of groups that claimed to be the true inheritors of the covenant of Israel. Most of these groups, such as the Sadducees, Pharisees, and the authors of at least some of the Dead Sea scrolls, would ultimately wither away. But by 640 $\mathrm{CE}$ two of these groups began to crystallize into the religions that we now somewhat roughly label as "Christianity" and "Rabbinic Judaism."

This wiki does not claim to tell a coherent story of this transformation. It instead offers three kinds of resources for exploring the fascinating history of this period. First are three contextual essays that attempt to integrate into a concise narrative the history of the three major political periods. Second is a collection of important themes, and finally many shorter entries on names, texts, topics, etc. The entries are linked extensively to each other, providing many ways to browse and navigate the wiki.

This is a work in progress! Enjoy and, in the democratic although frightening spirit of the wiki, feel free to comment and provide feedback.

Contextual Essays

- Persian Period: 539 to 334 BCE

- Hellenistic Period: 334 to 63 BCE

- Roman Period: $63 \mathrm{BCE}$ to 4th century CE

Thematic Essays

- Conversion

- Ethnicity

- Jews and Gentiles 
Teaching Ancient Jewish History: An Experiment in Engaged Learning

- Priests

- Religious Authority

- Revolts

- Rituals

- Sects

- Temple

- Texts

- Women

- Prophecy

Names, Texts, and Other Important Things

- Ezra

- Haggai

- Nehemiah

- Zechariah

- Mishnah

- Philo

- Josephus

- Rabbi Judah

- Enoch

- Jesus

- Samaritans

- Septuagint

- Tanakh

- Maccabees

- Herod

- Pseudepigrapha

- Apocrypha

- Wisdom of Solomon

- Alexander the Great

- Ecclesiastes

- Jubilees

- Hasmoneans

- Pharisees

- Saducees

- Essenes

- Qumran/Dead Sea Scroll Community 